\title{
A Study on the Relationship between Money Supply and Macroeconomic Variables in China
}

\author{
Yugang He, Ph.D. \\ Department of International Trade Graduate School, \\ Chonbuk National University, South Korea
}

Doi: $10.1515 / m j s s-2017-0046$

\begin{abstract}
Many scholars have examined the importance of the money supply to the macroeconomics in developed countries. However, few studies have explored this proposition in developing countries. So, in this paper, annual series data from 2000 to 2016 is applied to analyze the relationship between the money supply $\left(\mathrm{M}_{2}\right)$ and the macroeconomic variables (the real GDP, the inflation rate \& the interest rate) under the vector auto regression (VAR) model in China. The purpose of this paper is to verify the impact of these variables on the money supply in China. After performing an empirical analysis, conclusions can be obtained that an increase in the real GDP can result in an increase in the money supply; Also, an increase in the inflation rate can lead to an increase in the money supply; Conversely, an increase in the interest rate can cause a decrease in the money supply. Therefore, via adjusting the change of real GDP, inflation rate and interest rate, a better control of the money supply can be performed for the policy-makers in China.
\end{abstract}

Keywords: Money Supply, Macroeconomic Variables, VAR Model

\section{Introduction}

The western press' reports and national leaders' words have been full of prejudices against China's rapid development since China became the second-largest economic entity in the world. Especially, the president of the United States of America, Donald John Trump, took office shortly, he declared that China is a currency manipulator. As a matter of fact, the reason why China achieves remarkable success in economic field is that good macroeconomic policies has be taken into effect. In particular, the monetary policy deserves to be mentioned most.

Monetary policy is an important instrument with which objectives of macroeconomic policy can be achieved. In China, the function of monetary policy is to maintain the currency's value stabilization so as to accelerate economic growth. In this paper, the money supply is treated as the explanatory variable (a type of independent variable that changes how everything else operates even though it is just a small thing). $M_{1}$ (currency plus demand deposits, traveler's checks, and other check-able deposits) and $M_{2}\left[M_{1}\right.$ plus retail money market mutual fund balances, saving deposits (including money market deposit accounts), and small time deposits] are treated as explanatory variable. In China, the People's Bank of China publishes the target values of $M_{1}$ and $M_{2}$ every year. Usually, there is a gap between the growth rate of the actual value and the target value of $M_{1} \& M_{2}$. However, since 2007, the People's Bank of China has abolished the target growth rate of $M_{1}$. And only that of $M_{2}$ is published. Basically, as the explanatory variable of monetary policy, it should be equipped with the features such as the availability and the pertinence. Namely, the People's Bank of China is able to control the explanatory variable through the control of monetary policy. The reason is that the fluctuation of explanatory variable can influence the price and the 
output.

The purpose of this study is to test the long-run relationship between the money supply and the macroeconomic variables ( output, inflation rate, interest rate) to demonstrate the validity of money supply which is as an explanatory variable. Another purpose is to verify that $M_{2}$ is better to be the explanatory variable of monetary policy than that of $M_{1}$ in China.

The consequence of this study shows that the excess money supply $\left(M_{2}\right)$ can result in a rise in the inflation in the short run. It certifies that the People's Bank of China sets the money supply as the explanatory variable which is valid and effective. $M_{1}$ is endogenous and determined by the economic development level and the holding of the liquidity costs of the money demand. $M_{2}$ is exogenous and determined by the monetary policy of the People's Bank of China because it is difficult for the People's Bank of China to regulate the aim controlling of $M_{1}$. When taking the availability and the pertinence into consideration, $M_{2}$ is better to be treated as the explanatory variable of monetary policy.

This paper includes five parts. Part 1 is the introduction; Part 2 provides the literature review which provides some findings from the previous studies; Part 3 provides the methodology which is a basis for conducting the empirical analysis; Part 4 presents the empirical analysis which verifies the relationship among variables; Part 5 provides some conclusions.

\section{Literature Review}

There are a large quantity of scholars who apply different kinds of multiple linear regression models to analyze the dynamic correlation between the money supply and the economic growth as well as inflation. Of course, their results are often different.

Babatunde and Shuaibu (2011) find a monetary growth model for Nigeria by examining the existence of a significant long-run relationship between money supply, inflation and growth as well as to identify the possible determinants of portfolio holdings to identify the main economic fundamentals that influence the relationship between 1975 and 2008. Their study makes use of error correction mechanism and the bounds testing approach to cointegration within an auto regressive distributed lag framework. Quantitative evidences reveal that there is a positive relationship between money supply, capital formation and economic growth in Nigeria while there is a negative relationship between inflation and growth. However, Sabade (2013) figures that monetary policy always has its own limitations and it's high time we understood them. The quantity theory of money gives the identity. Namely, $M V=P T$ which is true. But the functional relationship between $M$ and $P$, that is, $P=f(M)$ does not hold in India since it's based on the constancy of $V$ and $T$. So when inflation happens that it need not be attributed to money supply alone. In fact, even if a greater than required money supply has caused it, there is no guarantee that reduced money supply will bring inflation down. Also, Dragos, Mihaela and Stefan (2013) reveal that China directly controls the money supply through the uncontrolled printing of money. China has proved countless times that reaching economic growth is the main goal, and the means do not matter as long as the growth is present. Normally, according to the economic theory the growth of money supply will self-acting lead to inflation. This study proves that this theory is only available in the USA. Thus, for a growth of $1 \%$ in the money supply there will be a growth in inflation of $8 \%$. For a growth of $1 \%$ in the interest rate, the inflation will grow by $0.6 \%$. Chaudhry, Farooq and Murtaza (2015) publish a paper called "Monetary Policy and its Inflationary Pressure in Pakistan." Their findings go over the main points; interest rate and money supply are important policy variables for controlling inflation in the long run while it is the national output level which put downward pressure on inflation rate in the short run. Meanwhile, Jayasooriya (2015) also recaps that the expansion monetary policy causes to increase the inflation in Sri Lanka and one reason for the expansive monetary policy is the budget deficit. On the other hand inflation also causes to increase the budget deficit. Therefore, these relationships show a vicious cycle of inflation in Sri Lanka. Recently, Hung and Thompson (2016) explore that using data for 23 OECD countries from 1960 to 2009 demonstrates that workers' power has a larger effect on the inflation rate than money growth. Behera (2016) performs that the cointegration result shows that there is at least one linear combination in the long run and hence there is a long-run equilibrium relationship between variables in the model, which suggests that money supply and the exchange rate has a positive effect on the GDP 
growth in the economy. The error correction results indicate that correct and negative sign for gross domestic product and exchange rate. Lastly, Srithilat and Sun (2017) write an article, named "The Impact of Monetary Policy on Economic Development: Evidence from Lao PDR". Their findings reveal that changing on the stock of money supply will have a negatively effect on the economic development in the long run. The relationship between money supply and gross domestic product per capita is negatively significant. Moreover, the crucial element of monetary policy instrument which driven the economic development of Lao PDR in the long run are interest rate and exchange, these two independent variables have a positive sign and their contribution to gross domestic product per capita are much more higher than money supply. However, the long-run relationship between inflation also confirms the negative relationship between money supply and real gross domestic product per capita, meaning that whenever the money supply has been rising would increase inflation and decreases in real output.

In this paper, the main aim is to verify the relationship between money supply and macroeconomic variables (real GDP, inflation rate, interest rate) in China. And the analysis results suggest that the inflation and the real GDP have a positive effect on money supply. Conversely, the interest rate has a negative effect on money supply.

\section{Methodology}

\subsection{Suitability Test of $\mathrm{M}_{1} \& \mathrm{M}_{2}$}

$M_{1}$ is the sum of the currency plus demand deposits, traveler's checks, and other check-able deposits. The purpose of holding $M_{1}$ is to treat it as a media exchange to purchase the commodity, labor services and securities. It is most liquid financial asset that is held by public. $M_{2}$ is sum of $M_{1}$ and the near money which is the sum of the resident savings deposits, time deposit of enterprises and other deposits. And it can not directly use as media exchange to buy commodity and labor services. If $M_{2}$ wants transacting, $M_{2}$ should need to be extracted from the bank and transferred into $M_{1}$. Therefore, $M_{1}$ can be treated as the money in circulation; $M_{2}$ is the money stock.

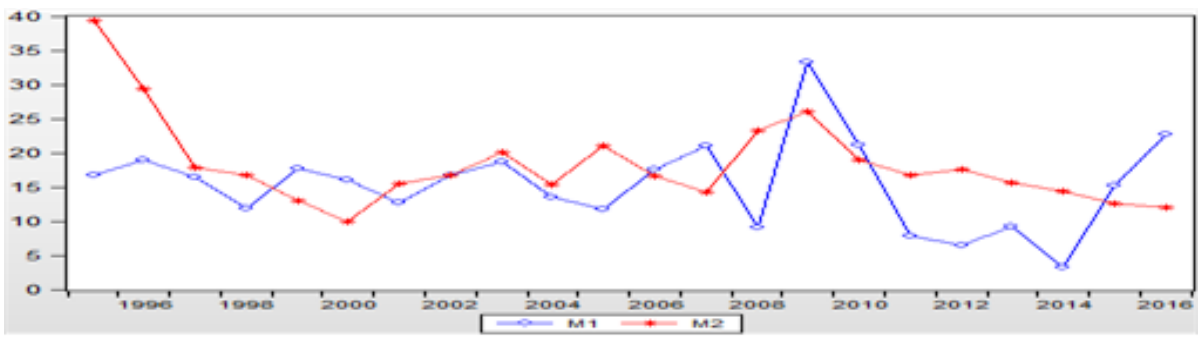

Fig. 1: Year-on-Year Growth Rate of $M_{1} \& M_{2}$

Source: People's Bank of China

Fig.1. shows the volatility of $M_{1} \& M_{2}$ 's growth. $M_{1}$ is relatively steady and $M_{2}$ is in a great fluctuation. In different periods of economic activities, $M_{1} \& M_{2}$ often perform differently. For example, when the economy locates in the low point, the growth rate of $M_{1}$ is usually lower than that of $M_{2}$. Meanwhile, the commodity and labor service's demand is also in the lower level. Conversely, when the growth rate of $M_{1}$ exceeds that of $M_{2}$, enterprises often transfer their time deposits into demand deposits in a large amount so as to pay for outgoings. Meanwhile, enterprise's will to invest and the economy boom will turn better.

$M_{1}$ has a stronger endophytism than that of $M_{2}$. Therefore, when the People's Bank of China is ready to loosen monetary, a stimulation needs to be attached into $M_{2}$ 's growth. However, if the total demand does not reach a active degree, $M_{1}$ still keeps in a low growth rate. Only when a rise in active degree of economic operation of itself, $M_{1}$ will increase quickly. So, $M_{2}$ will be adopted to analyze in this paper. 


\subsection{Long-run Market Equilibrium}

In the long run, the money market equilibrium will be shocked by the price level, nominal interest rate. When the real money supply (determined by the central bank) equals the demand for real money balances (determined by the nominal interest rate and real income), the money market will be in equilibrium. Thus, a general model in which money demand is proportional to nominal income, and a deceasing function of the nominal interest rate:

$$
M=L(i) \times P Y
$$

$M$ is the demand for money; $L(i)$ is a decreasing function of the nominal interest rate; $P$ is the price level; $Y$ is the real income. Dividing by , the money market equilibrium can be derived:

$$
\frac{M}{Y}=L(i) \times Y
$$

$\frac{M}{P}$ is the supply of real money; $L(i) \times Y$ is the demand for real money.

An economist, called Juselius, proposes an idea on this proposition. His results show that the real total money can not always determine the money demand, unless backing to equilibrium can be completely performed in the instant. In general, the total money observed probably is determined by money supply, money demand and a combination of them. If the Central Bank can control the money supply effectively, the money supply will be adjusted to the money demand. the total money observed pretty probably is determined by the money supply.

Assuming that the total money, $M_{2}$ is determined by the money demand, in the money demand theory, the total money is determined by the transaction demand, wealth demand and opportunity cost. Also the transaction demand of $M_{2}$ can be measured by the real GDP. A scholar, called Qin, has performed a empirical study on money wealth demand in China. Her findings show that the real income and real interest rate are the main factors that determine the money wealth demand. This finding will be used in this paper.

The real money demand of $M_{2}$ gives:

$$
M_{2 t}=\alpha_{1}+\alpha_{2} y_{t}+\alpha_{3} p_{t}+\alpha_{4} R_{t}+\varepsilon_{t}
$$

Where $\alpha_{2} \geq 0, \quad \alpha_{3} \geq 0, \quad \alpha_{4} \leq 0 ; y_{t}$ stands for the real; $p_{t}$ stands for the inflation; $R_{t}$ stands for the deposit rate.

\section{Empirical Analysis}

\subsection{Data Description}

In this paper, four variables are involved. The real total money $\left(M_{2}\right)$ is the ratio of nominal total money to CPI; The real GDP $\left(y_{t}\right)$ is the ratio of nominal GDP to CPI; The inflation rate $\left(\hat{p}_{t}\right)$ is the ratio of $C P I_{t}$ to $C P I_{t-1}$; The deposit interest rate for one year is $R_{t}$. The definition, meaning and the source of the variables are shown in table.1.

Table 1. Estimation Variables

\begin{tabular}{l|l|l|l}
\hline Variable & Meaning & Definition & Source \\
\hline$m_{2 t}$ & Real total money $M_{2}$ & $m_{2 t}=\log \left(\frac{M_{2 t}}{C P I_{t}}\right)$ & $\begin{array}{l}\text { National Bureau of statistics of the } \\
\text { People's Republic of China }\end{array}$ \\
\hline$y_{t}$ & real GDP & $y_{t}=\frac{G D P_{t}}{C P I_{t}}$ & $\begin{array}{l}\text { National Bureau of statistics of the } \\
\text { People's Republic of China }\end{array}$ \\
\hline$\hat{p}_{t}$ & Year-on-year inflation rate & $\hat{p}_{t}=\log \left(\frac{C P I_{t}}{C P I_{t-1}}\right)$ & $\begin{array}{l}\text { National Bureau of statistics of the } \\
\text { People's Republic of China }\end{array}$ \\
\hline$R_{t}$ & Deposit interest rate for one year & $R_{t}$ & $\begin{array}{l}\text { National Bureau of statistics of the } \\
\text { People's Republic of China }\end{array}$ \\
\hline
\end{tabular}




\subsection{Unit Root Test}

When a time-series regression approach is used to study the relationship among time series, it is important to test the stationary of the original sequence first. The reason is that, even though the sequence is non-stationary, the result of the regression test finds that the relationship among the sequences may be notable. In fact, this kind of regression is spurious regression. Therefore, it is necessary to test the stationary of the logarithm sequence of variables.

The ADF test is completed by the following three models:

Model 1:

$$
\Delta X_{t}=\delta X_{t-1}+\sum_{i=1}^{m} \beta_{i} \Delta X_{t-1}+\varepsilon_{t}
$$

Model 2:

$$
\Delta X_{t}=\alpha+\delta X_{t-1}+\sum_{i=1}^{m} \beta_{i} \Delta X_{t-1}+\varepsilon_{t}
$$

Model 3:

$$
\Delta X_{t}=\alpha+\beta \mathrm{t}+\delta X_{t-1}+\sum_{i=1}^{m} \beta_{i} \Delta X_{t-1}+\varepsilon_{t}
$$

The null hypothesis, $H_{0}: \delta=0$, one unit root exists; An alternative hypothesis, $H_{1}: \delta \neq 0$, a unit root does not exist.

The difference between model 1 and the other two models is that the other two models have constant and trend term. Actually, the proper order to test the sequence is from the model 3 to model 1. Any test that rejects the null hypothesis means that its original sequence does not have a unit root. As long as one of the results from any of the models rejects the null hypothesis, the original hypothesis can be considered to be stationary. When all of the testing results of the three models do not reject the null hypothesis, the original sequence can be considered to be nonstationary. And then, the first difference of the original sequence should be tested, and the procedures above should be repeated until becoming stationary.

Table. 2 shows the unit root test of the original sequence and its first difference.

Table 2. Result of unit root test

\begin{tabular}{c|c|c|c}
\hline Variable & ADF Test Statistic & P-value & Test critical value 5\% \\
\hline$m_{2 t}$ & 0.011 & 0.946 & -3.081 \\
\hline$y_{t}$ & -0.577 & 0.844 & -3.120 \\
\hline$\hat{p}_{t}$ & -0.082 & 0.711 & -3.145 \\
\hline$R_{t}$ & -1.961 & 0.298 & -3.099 \\
\hline$\Delta m_{2 t}$ & -3.822 & 0.014 & -3.099 \\
\hline$\Delta y_{t}$ & -4.192 & 0.008 & -3.112 \\
\hline$\Delta \hat{p}_{t}$ & -5.875 & 0.000 & -3.099 \\
\hline$\Delta R_{t}$ & -3.983 & 0.041 & -3.099 \\
\hline$\Delta$
\end{tabular}

$\Delta$ stands for the first difference.

Table. 2 shows all variables are non-stationary under the $5 \%$ significance level. However, after first difference, all of them become stationary under the $5 \%$ significance level. 


\subsubsection{Choice of lag difference on the model}

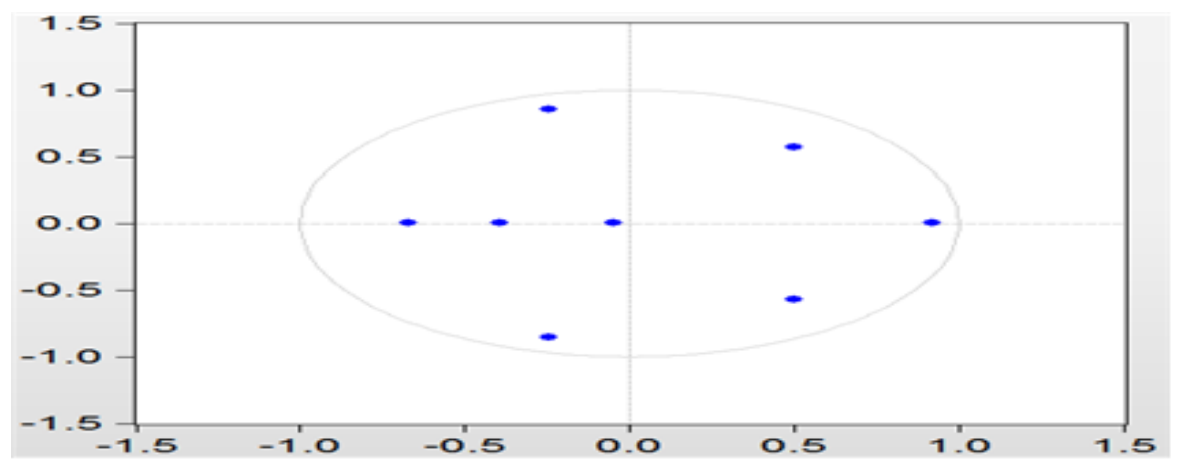

Fig. 2: Inverse Roots of AR Characteristic Polynomial

Unless roots of VAR model' reciprocal is less than 1. Namely, all points are located in the unit cycle, the model will be stationary. Fig. 1 indicates that this model is stationary because all points are in the unit sycle.

After confirming the stationary of this model, using the VAR model's Lag Order Selection Criteria can determine the lagged difference between the money supply and others from 2000 to 2016 in China. And the results show in table. 2.

Table 2. VAR Model Lag Order Selection Criteria

\begin{tabular}{c|c|c|c|c|c|c}
\hline Lag & LogL & LR & EPE & AIC & SC & HQ \\
\hline 0 & 94.426 & NA & 2.891 & -12.918 & -12.735 & -12.935 \\
\hline 1 & 119.577 & 32.337 & 8.900 & $-14.225^{*}$ & $-13.312^{*}$ & -14.310 \\
\hline 2 & 140.672 & 15.068 & 9.852 & -14.953 & -13.310 & -15.105 \\
\hline
\end{tabular}

${ }^{*}$ indicates lag order selected by the criterion

Table. 2 indicates that according to AIC and SC, the lagged difference is lag 1. Based on this, $\operatorname{VAR}(1)$ model whose variables are $m_{2 t}, y_{t}, \hat{p}_{t}$ and $R_{t}$ can be established. The estimated results gives:

$$
\begin{aligned}
& m_{2 t}=-0.134 m_{2 t}(-1)+0.262 \hat{p}_{t}(-1)-0.055 R_{t}(-1)+1.340 y_{t}(-1)-0.506 \\
& p_{t}=0.686 m_{2 t}(-1)-0.268 \hat{p}_{t}(-1)+0.010 R_{t}(-1)-0.809 y_{t}(-1)+1.514 \\
& R_{\mathrm{t}}=4.049 m_{2 t}(-1)+0.264 \hat{p}_{t}(-1)+0.897 R_{t}(-1)-5.258 y_{t}(-1)+3.245 \\
& y_{t}=-0.192 m_{2 t}(-1)+0.188 \hat{p}_{t}(-1)+0.003 R_{t}(-1)+1.191 y_{t}(-1)-0.094 \\
& R^{2}=0.998 ; \text { AIC }=-5.037 ; S C=-4.801
\end{aligned}
$$

Estimating equation models demonstrate that the fitting degree of models is better. And the value of AIC and SC are small, which illustrates the model structure is steady. Also, it shows that auto correlation and heteroscedasticity does not exist.

\subsection{Model Test}

\subsubsection{Granger Causality test}

After establishing model, the causality among all variables should be confirmed. 
Table 3. Granger Causality test

\begin{tabular}{l|c|c|l}
\hline Null Hypothesis & F-statistic & P-value & Result \\
\hline$\hat{p}_{t}$ does not Granger Cause $m_{2 t}$ & 5.877 & 0.031 & Rejected \\
\hline$m_{2 t}$ does not Granger Cause $\hat{p}_{t}$ & 0.864 & 0.454 & Non-rejected \\
\hline$R_{t}$ does not Granger Cause $m_{2 t}$ & 6.065 & 0.022 & Rejected \\
\hline$m_{2 t}$ does not Granger Cause $R_{t}$ & 0.753 & 0.498 & Non-rejected \\
\hline$y_{t}$ does not Granger Cause $m_{2 t}$ & 4.486 & 0.045 & Rejected \\
\hline$m_{2 t}$ does not Granger Cause $y_{t}$ & 2.834 & 0.111 & Non-rejected \\
\hline
\end{tabular}

Table. 3 shows the hypothesis that $\hat{p}_{t}$ does not Granger Cause $m_{2 t}$ is rejected and $m_{2 t}$ does not Granger Cause $\hat{p}_{t}$ is non-rejected. It means that it is a unidirectional causality from $\hat{p}_{t}$ to $m_{2 t}$ under $5 \%$ significance level. Moreover, the conclusion that $\hat{p}_{t}$ does not Granger Cause $m_{2 t}$ is rejected is in accordance with this paper discussed. It indicates the fact that in the long run the inflation can result in an increase in money supply in China, which is significant; Taking the long-run relationship between money supply and interest rate into account, a unidirectional causality between money supply and interest rate exists under $5 \%$ significance level. Namely, the money supply and interest rate have an unilateral effects. And Granger causality test result is in keeping with this paper addressed. It also indicates that in the long run an increase in the interest rate can lead to a decrease in money supply in China; In addition, table. 3 also implies that there is a long-run relationship between money supply and real $G D P$, and a unidirectional causality from real GDP to money supply. The hypothesis that $m_{2 t}$ does not Granger Cause $y_{t}$ is non-rejected and $y_{t}$ does not Granger Cause GDP is rejected under $5 \%$ significance level. It demonstrates that in the long run the real GDP can promote and expansion of money supply in China.

\subsubsection{Impulse Response Function}
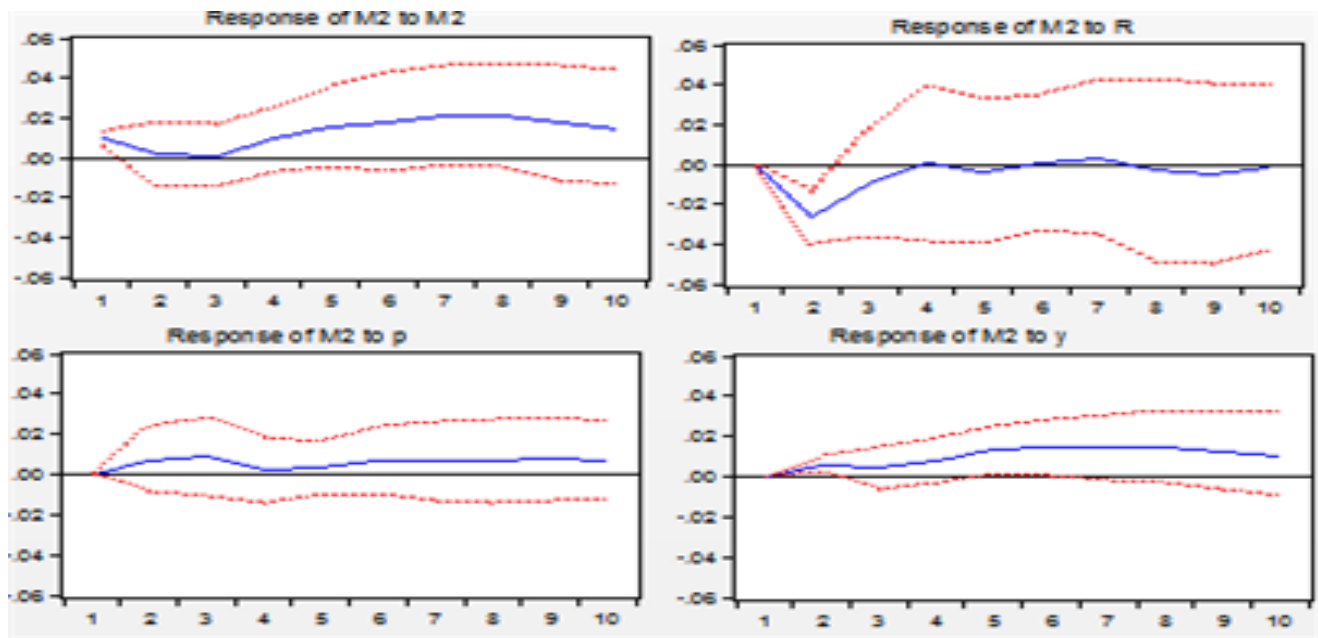

Fig. 3: Impulse response function

The impulse response functions show the reaction of the different variables' impluses to the dependent variable. As for response of $m_{2 t}$ to $m_{2 t}$, the money supply performs a rise on itself response; As for response of $m_{2 t}$ to $R_{t}$, the interest rate has a negative effect on the money supply. At lag 2, its effect arrives at minimum. However, its effect always keeps under the negative area. As for response of $m_{2 t}$ to $\hat{p}_{t}$, the inflation rate has a positive effect on the money supply. After lag 10, its effect on the money supply will keep constant. As for response of $m_{2 t}$ to $y_{t}$, the real GDP also 
has a positive effect on the money supply. And in the short run, its effect on the money supply keeps growing. But in the long run, its effect will fall to zero.

\subsubsection{Variance Decomposition}

Table 4. Variance Decomposition of $m_{2 t}$

\begin{tabular}{c|c|c|c|c|c}
\hline Period & S.E & $m_{2 t}$ & $\hat{p}_{t}$ & $R_{t}$ & $y_{t}$ \\
\hline 1 & 0.009 & 100.000 & 0.000 & 0.000 & 0.000 \\
\hline 2 & 0.030 & 9.531 & 5.715 & 81.128 & 3.627 \\
\hline 3 & 0.033 & 7.988 & 11.504 & 75.731 & 4.777 \\
\hline 4 & 0.035 & 13.873 & 10.307 & 66.315 & 9.505 \\
\hline 5 & 0.041 & 23.807 & 8.170 & 50.293 & 17.728 \\
\hline 6 & 0.047 & 32.074 & 8.116 & 37.668 & 22.142 \\
\hline 7 & 0.054 & 39.451 & 7.535 & 29.173 & 23.841 \\
\hline 8 & 0.600 & 43.806 & 7.710 & 23.920 & 25.105 \\
\hline 9 & 0.064 & 45.157 & 7.629 & 21.492 & 25.722 \\
\hline 10 & 0.067 & 46.132 & 8.013 & 19.801 & 26.054 \\
\hline
\end{tabular}

Variance Decomposition measures the contribution of each explanatory variable to the expected change of explained variable. It is useful in assessing how changes to economic variables reverberate through a system.

Table. 4 indicates that in the trend of Chinese money supply growth, the expected variance of Chinese money supply growth is determined by the disturbance from itself in the lag 1 . However, in the lag 2, $9.531 \%$ of Chinese money supply growth is from itself; $5.715 \%$ of Chinese supply money growth is from the inflation; $81.128 \%$ of Chinese money supply growth is from interest rate; $3.627 \%$ of Chinese money supply growth is from the real GDP. Then, if taking the long-run effect into consideration, Chinese money supply growth is mainly determined by itself up to $50 \%$, of course, still $8 \%$ from inflation, $14 \%$ from interest rate and $28 \%$ from real GDP.

\section{Conclusion}

In this paper, most emphasis has been put on the relationship between the money supply, $m_{2 t}$, and macroeconomic variables (real GDP, inflation rate, interest rate) in China. Then VAR model is established and the data is gotten from National Bureau of statistics of the People' s Republic of China with the year from 2000 to 2016 . Based on two of them, an empirical analysis is conducted and the empirical analysis findings reveal that in China an increase in the real GDP can result in an increase in the money supply; Meanwhile, an increase in the inflation rate can lead to an increase in the money supply; Oppositely, an increase in the interest rate can cause a decrease in the money supply. So, the results of this paper provide a better reference for the policy-makers controlling the money supply in China.

\section{References}

Jayasooriya, D. (2015). Money Supply and Inflation: Evidence from Sri Lanka. Asian Studies International Journal, 1(1), 22-28

Hung, H. F., \& Thompson, D. (2016). Money Supply, Class Power, and Inflation: Monetarism Reassessed. American Sociological Review, 81(3), 447-466.

Chaudhry, I. S., Farooq, R. I. F., \& Murtaza, G. (2015). Monetary policy and its inflationary pressure in Pakistan. Pakistan Economic and Social Review, 53(2), 251.

Behera, J. (2016). Dynamics of Inflation, Economic Growth, Money Supply and Exchange Rate in India: Evidence from Multivariate Analysis. Quarterly Journal of Econometrics Research, 2(2), 42-54.

Juselius, K. (2009). Special issue on using econometrics for assessing economic models: an introduction.

Srithilat, K., Sun, G., \& Thavisay, M. (2017). The Impact of Monetary Policy on Economic Development: Evidence from Lao PDR. Global Journal of Human-Social Science Research. 
Babatunde, M. A., \& Shuaibu, M. I. (2011). Money Supply, Inflation and Economic Growth in Nigeria. Money Supply, Inflation and Economic Growth in Niger, 11(1), 147-163.

Dragos, P., Mihaela, S., \& Stefan, M. (2013). The Influence of Money Supply and Interest Rate on Inflation. China-USA Business Review, 12(6).

Qin, D., Quising, P., He, X., \& Liu, S. (2005). Modeling monetary transmission and policy in China. Journal of Policy Modeling, 27(2), 157-175.

Sabade, S. (2014). Is money supply the cause of inflation in India? An alternative postulate to understand inflation. Procedia-Social and Behavioral Sciences, 133, 379-382. 